\title{
IDENTIFIKASI POTENSI DAN DAYA TARIK WISATA KHDTK BULUH CINA KABUPATEN KAMPAR PROVINSI RIAU
}

\section{Identification Of KHDTK Tourism Potential and Attractions Cina Regency Kampar Regency, Riau Province}

\author{
Hadinoto $^{1}$, Dodi Sukma ${ }^{2}$, Eni Suhesti ${ }^{3}$ \\ 1,2,3) Fakultas Kehutanan Universitas Lancang Kuning, Jalan Yos Sudarso KM 8 (Pekanbaru, Riau \\ 28266, Indonesia) \\ Email:hadinoto@unilak.ac.id,dodisukma@unilak.ac.id,suhestieni@unilak.ac.id
}

Diterima: 02 Agustus 2021, Direvisi: 03 Agustus 2021, Disetujui: 24 Januari 2022

DOI: 10.31849/forestra.v17i1.7441

\begin{abstract}
KHDTK has an area of 103 hectares, more than $70 \%$ of the KHDTK area contains palm oil. And less than $30 \%$ there is forest area in it. It is necessary to identify the potential in the area. The purpose of the study was to identify the potential and tourist attraction of KHDTK Buluh Cina, Kampar Regency, Riau Province. The measurement of potential uses the One Score-One Indicator System, namely giving a score of 1 (one), for 1 (one) indicator, with the scale used is 1-7 (which is a development of the Likert scale 1-5). The use of a scale of 1-7 is applied because it is in accordance with the character of the Indonesian people who articulate a value in great detail (Avenzora 2008). The results of the research on the Assessment of Tourism Potential and Attractiveness of the Chinese Reeds KHDTK for oil palm stretches have a value of (3.23) which is somewhat unattractive, due to difficult access to entry, and the status of land conflicts. Forest area has potential and attractiveness value (3.39) which is somewhat unattractive, because it is dominated by oil palm. Assessment of Supporting Potentials Sandy river banks have potential and attractiveness values (4.43) which are sufficient, because there are no managers and supporting facilities. The Assessment of Fishing Potential in the River (4.6) is rather interesting, because the Kampar River is a suitable place for fishing.
\end{abstract}

Keywords: potential tourist, attraction of Buluhchina

\begin{abstract}
ABSTRAK
KHDTK memiliki luas kawasan sebesar 103 hektare, lebih dari 70\% isi kawasan KHDTK terdapat hamparan sawit. Serta kurang dari 30\% terdapat kawasan hutan didalamnya. Perlu dilakukan identifikasi potensi di Kawasan tersebut. Tujuan penelitian Mengidentifikasi Potensi dan Daya Tarik Wisata KHDTK Buluh Cina Kabupaten Kampar Provinsi Riau. Pengukuran potensi menggunakan One ScoreOne Indicator System, yakni pemberian skor 1 (satu), untuk 1 (satu) indikator, dengan skala yang digunakan adalah 1-7 (merupakan pengembangan dari skala Likert 1-5). Penggunaan skala 1-7
\end{abstract}


diterapkan karena sesuai dengan karakter masyarakat Indonesia yang mengartikulasikan suatu nilai dengan sangat detail (Avenzora 2008). Hasil penelitian Penilaian Potensi dan Daya Tarik Wisata KHDTK Buluh Cina untuk Hamparan sawit memiliki nilai (3.23) yaitu agak tidak menarik, karena akses masuknya yang sulit, dan status konflik lahan. Kawasan Hutan memiliki nilai potensi dan daya tarik (3.39) yaitu agak tidak menarik, karena didominasi dengan sawit. Penilaian Potensi Pendukung Tepian sungai berpasir memiliki nilai potensi dan daya tarik (4.43) yaitu cukup, karena belum ada pengelola, fasilitas pendukung. Penilaian Potensi Memancing di Sungai (4.6) yaitu agak menarik, karena Sungai Kampar tempat yang cocok untuk memancing.

Kata kunci : potensi daya tarik, wisata buluhcina

\section{PENDAHULUAN}

Kawasan Hutan Dengan Tujuan

Khusus (KHDTK) adalah kawasan hutan yang secara khusus diperuntukkan untuk kepentingan penelitian dan pengembangan kehutanan, pendidikan dan pelatihan kehutanan serta religi dan budaya. Melalui Menteri Lingkungan Hidup dan Kehutanan (LHK) Dr. Siti Nurbaya Bakar menyerahkan SK KHDTK kepada Fakultas Kehutanan Universitas Lancang Kuning (Unilak) untuk mengelola sebuah Kawasan Dengan Tujuan Khusus (KHDTK) hutan pendidikan. Lokasi KHDTK hutan pendidikan berada di dalam kawasan Taman Wisata Alam (TWA) Buluh Cina, Kecamatan Siak Hulu, Kabupaten Kampar, Riau dengan luasan sekitar 103 hektare. Dengan luasan tersebut, lebih dari $60 \%$ isi kawasan KHDTK terdapat hamparan sawit. Serta kurang dari $40 \%$ terdapat kawasan hutan didalamnya. Untuk itu perlu dilakukan sebuah identifikasi potensi didalam kawasan tersebut, agar potensi yang ada dapat terpetakan dengan baik serta meminimalisir konflik sosial terhadap pemilik sawit.

Identifikasi potensi gunanya agar bisa dijadikan sebuah daerah tujuan wisata didalam kawasan KHDTK Buluh cina. Potensi yang ada bisa dijadikan Daya tarik wisata, menurut Gunn (1994) sesuatu yang ada di lokasi destinasi atau/tujuan pariwisata yang tidak hanya menawarkan/menyediakan sesuatu bagi wisatawan untuk dilihat dan dilakukan, tetapi menjadi magnet penarik seseorang untuk melakukan perjalanan.

Ciri utama daya tarik wisata adalah tidak dapat dipindahkan dan untuk menikmatinya wisatawan harus datang ke tempat tersebut. 
Daya tarik wisata yang juga disebut obyek wisata merupakan potensi yang menjadi pendorong kehadiran wisatawan ke suatu daerah tujuan wisata. Pada masa sekarang telah terjadi perubahan berwisata dari wisata masal (mass tourism) menjadi pola berwisata individu atau kelompok kecil, yang lebih fleksibel dalam perjalanan berwisata dan wisatawan dapat berinteraksi lebih tinggi dengan alam dan budaya masyarakat, seiring dengan pergeseran bentuk pariwisata internasional pada awal dekade delapan puluhan (Fandeli, 1999 dalam Demartoto Argyo, 2009).

Kawasan KHDTK yang luasnya 103 hektare tersebut tepatnya dijadikan sebuah Ekowisata. Ekowisata sebagai kegiatan perjalanan wisata yang dikemas secara professional, terlatih dan memuat unsur pendidikan sebagai suatu sektor ekonomi yang mempertimbangkan warisan budaya, partisipasi dan kesejahteraan penduduk lokal serta upaya-upaya konservasi sumber daya alam dan lingkungan (Nugroho). Berdasarkan uraian yang dikemukakan di atas, maka penulis tertarik untuk mengidentifikasi potensi dan daya tarik KHDTK Buluh cina sehingga kedepan bisa dilakukan pengembangan ekowisata.

\section{METODE PENELITIAN}

A. Pelaksanaan Penelitian

Penelitian ini dilaksanakan di KHDTK Buluh Cina Kabupaten Kampar Provinsi Riau. Penelitian dilakukan selama \pm 1 tahun meliputi kegiatan persiapan, penelitian lapangan, pengolahan data dan penyusunan laporan.

\section{B. Ukuran dan Kepentingan Desain Studi}

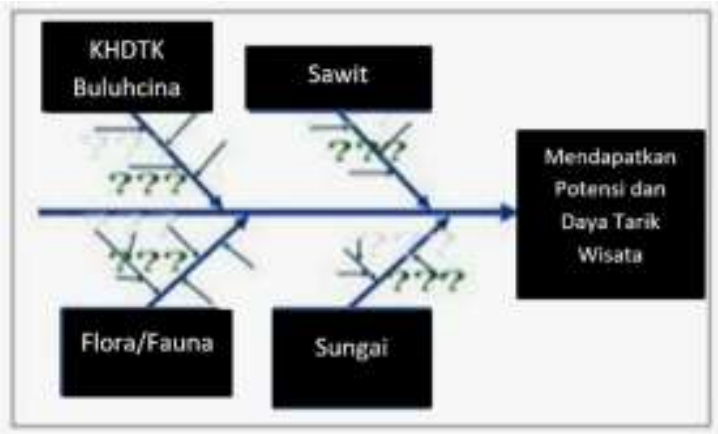

Gambar 1. Kerangka Penelitian

C. Bahan dan Alat

Bahan dalam penelitian adalah seluruh potensi dan daya tarik yang terdapat di kawasan KHDTK Buluh Cina Kabupaten Kampar Provinsi Riau. Sedangkan alat yang digunakan 
diantaranya adalah tabel tally sheet, teropong, GPS, alat tulis, dan kamera.

\section{Analisis Data}

Penelitian ini dilaksanakan di KHDTK Buluh Cina Kabupaten Kampar Provinsi Riau. Penelitian ini dimulai dari bulan September sampai Agustus 2021. Pengumpulan data dilakukan dengan cara observasi lapangan dan mengisi tally sheet potensi dan daya tarik wisata yang sudah disusun berdasarkan kriteria dan indikator. Analisis data menggunakan One ScoreOne Indicator System, yakni orservasi lapangan menggunakan tally sheet potensi dan daya tarik wisata yang sudah disusun berdasarkan kriteria dan indicator serta menilai dengan melakukan pemberian skor 1 untuk satu indikator, dengan skala yang digunakan adalah 1-7 (merupakan pengembangan dari skala Likert 1-5). Penggunaan skala 1-7 diterapkan karena sesuai dengan karakter masyarakat Indonesia yang mengartikulasikan suatu nilai dengan sangat detail (Avenzora 2008). Nilai skor 1-7 diberikan pernyataan sebagai berikut: (1) sagat tidak menarik
(2) tidak menarik (3) agak tidak menarik (4) ragu-ragu (5) agak menarik (6) menarik, dan (7) sangat menarik.

\section{HASIL DAN PEMBAHASAN}

\section{A. Penilaian Potensi dan Daya Tarik Wisata KHDTK Buluh Cina}

KHDTK adalah kawasan hutan yang secara khusus diperuntukkan untuk kepentingan penelitian dan pengembangan kehutanan, pendidikan dan pelatihan kehutanan serta religi dan budaya. Melalui Menteri Lingkungan Hidup dan Kehutanan (LHK) Dr. Siti Nurbaya Bakar menyerahkan SK KHDTK kepada Fakultas Kehutanan Universitas Lancang Kuning (Unilak) untuk mengelola sebuah Kawasan Dengan Tujuan Khusus (KHDTK) hutan pendidikan. Lokasi KHDTK hutan pendidikan berada di dalam kawasan Taman Wisata Alam (TWA) Buluh Cina, Kecamatan Siak Hulu, Kabupaten Kampar, Riau dengan luasan sekitar 103 hektare. Dengan luasan tersebut, lebih dari $70 \%$ isi kawasan KHDTK terdapat hamparan sawit.

Menurut data yang terdapat dilapangan saat melakukan penilaian KHDTK Buluh Cina menggunakan tabel tally sheet, kriteria penilaian terdiri terdiri dari; (1) Keunikan (2) Keindahan (3) Kelangkaan (4) Ketepatan Waktu 
Aksesibilitas (6) Sensitifitas (7) Fungsi Sosial dan Persepsi Nilai Potensi dan Daya Tarik Hamparan sawit (3.23) dan Hutan (3.39) agak tidak menarik, dengan demikian perlu dilakukan sebuah paket wisata pendukung agar semua potensi yang ada dapat menarik pengunjung untuk datang ke KHDTK Buluh Cina.

Menurut Brahmanto, 2015 Paket wisata (package tour, inclusive tour) diartikan sebagai suatu perjalanan wisata dengan satu atau lebih tujuan kunjungan yang disusun dari berbagai fasilitas perjalanan tertentu dalam suatu acara perjalanan yang tetap, serta dijual dengan harga tunggal yang menyangkut seluruh komponen dari perjalanan wisata. Sebelum memahami paket wisata, harus dipastikan apakah dalam rangkaian komponenkomponen wisata tersebut terdapat acara mengunjungi objek/atraksi wisata. Bila hanya paket perjalanan (transportasi) dan akomodasi saja, tidak dapat dikatakan paket tour. Paket Wisata disusun oleh Biro Perjalanan Wisata yang fungsinya sebagai mediator dan pengelola dari keseluruhan komponen pariwisata yang dibutuhkan oleh wisatawan selam melakukan kegiatan perjalanan wisatanya, haruslah memperhatikan bahwa produk yang disusunnya dapat memenuhi fungsinya sebagai alat bantu wisatawan dalam memenuhi kebutuhannya akan istirahat dan santai untuk kebugaran jasmani dan rohani serta menghilangkan kebosanan terhadap pekerjaan atau kegiatan rutinnya yang diharapkan dapat mengembangkan personality, pengungkapan sikap, mental, fisik dan spiritual.

Tabel 1. Penilaian Potensi dan Daya Tarik Wisata KHDTK Buluh Cina

\begin{tabular}{llccc}
\hline \multirow{2}{*}{ No } & & \multirow{2}{*}{ Penilaian Potensi } & \multicolumn{2}{c}{ SCORE } \\
& & A & B \\
\hline 1 & Keunikan & 3.20 & 3.70 \\
2 & Keindahan & 4.00 & 4.30 \\
3 & Kelangkaan & 3.00 & 3.30 \\
4 & Ketepatan Waktu/ Seasonability & 2.90 & 2.90 \\
\hline
\end{tabular}




\begin{tabular}{ccccc}
\hline \multirow{2}{*}{ No } & & \multirow{2}{*}{ Penilaian Potensi } & \multicolumn{2}{c}{ SCORE } \\
& & & A & B \\
\hline 5 & Sensitifitas & & 2.60 & 2.60 \\
6 & Aksesibilitas & 4.00 & 4.00 \\
7 & Fungsi Sosial & & 2.90 & 2.90 \\
\hline & & Skor Rata-rata & $\mathbf{3 . 2 3}$ & $\mathbf{3 . 3 9}$ \\
\hline
\end{tabular}

Sumber: Hasil Penelitian

\section{a. Hamparan Sawit}

Hamparan sawit memiliki nilai potensi dan daya tarik (3.23) yaitu agak tidak menarik, karena akses masuknya yang sulit, dan status lahannya yang masih belum jelas, serta ada klaim sepihak dari masyarakat yang menyatakan bahwa lahan tersebut milik mereka.

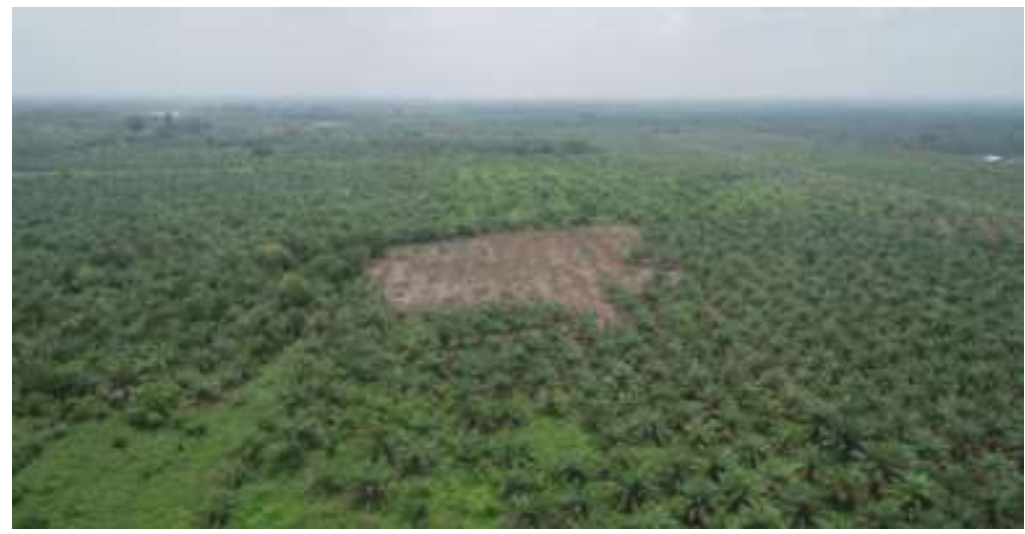

Gambar 2. Hamparan Sawit

\section{b. Kawasan Hutan}

Kawasan Hutan memiliki nilai potensi dan daya tarik (3.39) yaitu agak tidak menarik, karena kawasan hutan yang ada di KHDTK Buluh Cina kurang dari 30\%, selebihnya didominasi dengan sawit. Serta ada klaim sepihak dari masyarakat sekitar bahwasanya lahan tersebut adalah lahan mereka. Ketika peneliti masuk kedalam kawasan tersebut terjadi sedikit konflik yang 
mengaku adalah pemilik sawit. 


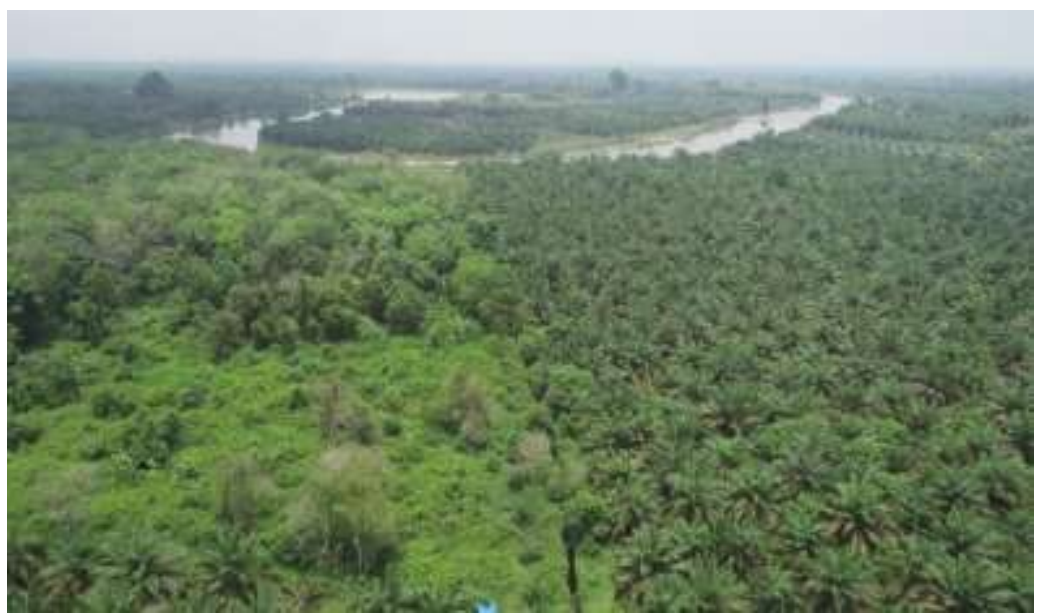

Gambar 3. Kawasan Hutan

\section{B. Penilaian Potensi dan Daya Tarik Wisata Pendukung}

Kawasan tepi sungai memiliki karakteristik/keunikannya tersendiri, tergantung dari keadaan geografis, sejarah serta budaya dan potensi-potensi lainnya yang dimiliki oleh daerah tersebut. Kawasan tepi sungai merupakan bagian elemen fisik suatu daerah yang sangat potensial untuk dikembangkan dan dijadikan suatu kawasan yang hidup dan tempat berkumpulnya masyarakat. Mengembangkan KHDTK Buluh Cina bukan hanya melihat kawasan hutan dan hamparan sawitnya saja tapi juga harus didukung dengan sebuah paket wisata, yang tujuannya untuk mendukung potensi yang ada sehingga dapat menarik pengunjung untuk datang ke KHDTK Buluh Cina, untuk itu kawasan tepi sungai dapat dimanfaatkan secara maksimal dan dikembangkan potensinya terutama didalam bidang pariwisata. Kawasan tepi sungai di KHDTK Buluh Cina dapat dikembangkan, mengingat posisinya yang strategis, hal ini dapat menarik minat para pengunjung untuk mengunjungi kawasan tepi sungai ini untuk rekreasi. Selain merupakan salah satu tujuan obyek wisata, kawasan tepi sungai di KHDTK Buluh Cina ini terdapat tepian berpasir juga dapat dijadikan sebagai camping ground. Adapun penilaian yang dilakukan menggunakan tabel tally sheet 
yaitu, kriteria penilaian terdiri terdiri dari; (1)

Keunikan (2) Keindahan (3) Kelangkaan (4)

Ketepatan Waktu (5) Aksesibilitas (6)

Sensitifitas (7) Fungsi Sosial dan Persepsi

Nilai Potensi dan Daya Tarik tepian sungai berpasir (4.43) cukup dan memancing di sungai (4.6) agak menarik, Menurut (Brahmanto, 2015) Dalam menarik wisatawan, maka diperlukan kreatifitas meramu paket paket wisata yang menarik. Dengan adanya paket wisata ini diharapkan mampu mendatangkan wisatawan dari luar negri lebih banyak dibandingkan tahun tahun yang lalu. Sehingga potensi tersebut perlu dikemas dengan baik sehingga menarik pengunjung untuk datang serta pengelolaan harus ditingkatkan agar semua potensi yang ada menjadi satu kesatuan paket wisata.

Tabel 2. Penilai Potensi dan Daya Tarik Wisata Pendukung

\begin{tabular}{lllcc}
\hline \multirow{2}{*}{ No } & & Penilaian Potensi & \multicolumn{2}{c}{ SCORE } \\
& & A & B \\
\hline 1 & Keunikan & 4.50 & 4.50 \\
2 & Keindahan & 5.00 & 4.50 \\
3 & Kelangkaan & 4.50 & 4.50 \\
4 & Ketepatan Waktu/ Seasonability & 4.00 & 5.00 \\
5 & Sensitifitas & 4.00 & 4.00 \\
6 & Aksesibilitas & 4.50 & 4.50 \\
7 & Fungsi Sosial & & 4.50 & 5.00 \\
\hline & & Skor Rata-rata & $\mathbf{4 . 4 3}$ & $\mathbf{4 . 6}$ \\
\hline
\end{tabular}

\section{c. Tepian Sungai Berpasir}

Tepian sungai berpasir memiliki nilai potensi dan daya tarik (4.43) yaitu cukup, karena potensi ini baru ditemukan dan belum ada pengelola, fasilitas pendukung. Kawasan ini seperti pantai memiliki pemandangan yang indah dan bisa dijadikan tempat camping. 


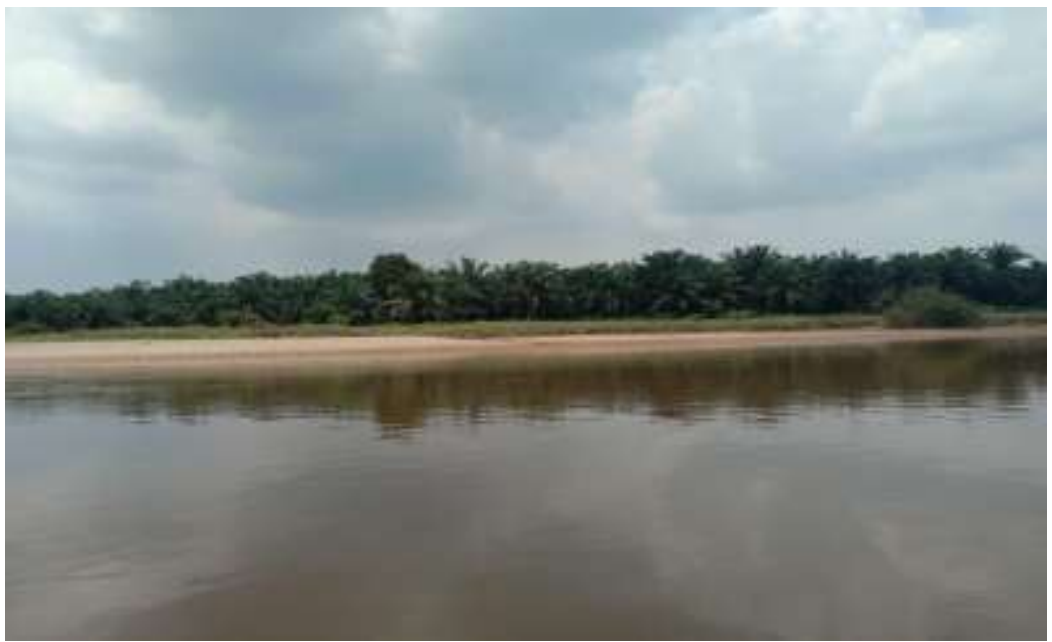

Gambar 4. Tepian sungai berpasir

\section{d. Memancing di Sungai}

Memancing di Sungai memiliki nilai potensi dan daya tarik (4.6) yaitu agak menarik, karena di Sungai Kampar Desa Buluh Cina ini terkenal dengan ikan tapa dan ikan baungnya, bagi yang hobi memancing selalu datang dengan menyewa kapal untuk memacing ikan tersebut. Wisata memancing memiliki daya tarik tersendiri bagi wisatawan yang hobinya memancing.

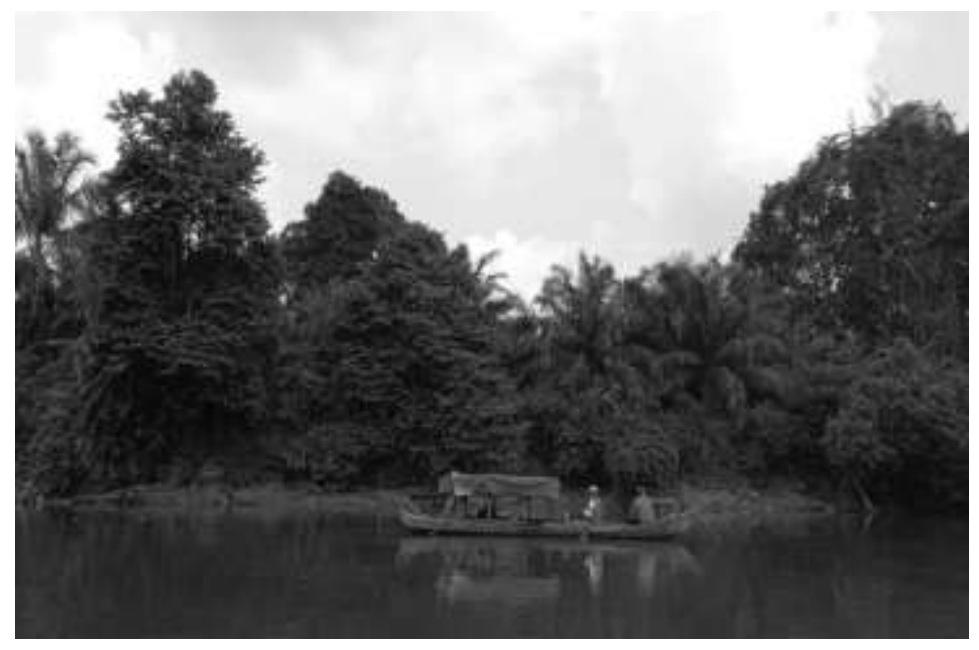

Gambar 5. Memancing di Sungai 


\section{Wahana Forestra: Jurnal Kehutanan} Vol. 17 No. 1 Januari 2022

Peranan sektor pariwisata dalam menunjang pembangunan nasional terus meningkat. Pariwisata juga merupakan salah satu sektor andalan untuk memperoleh devisa dari penghasilan non-migas. Selain perolehan devisa, pariwisata juga berperan dalam bidang-bidang strategis yang lain, misalnya menciptakan dan memperluas lapangan pekerjaan, mendorong pelestarian lingkungan hidup, mendorong pelestarian dan pengembangan budaya bangsa dan menumbuhkan rasa cinta tanah air. Rekreasi alam dapat diartikan sebagai suatu bentuk rekreasi dan pariwisata yang memanfaatkan potensi sumber daya alam dan ekosistemnya, baik dalam bentuk asli maupun buatan manusia. Sedangkan obyek wisata alam adalah alam beserta ekosistemnya baik asli maupun buatan manusia yang mempunyai daya tarik untuk dilihat dan dikunjungi wisatawan. Pembangunan dan pengembangan kawasan tepi sungai harus mengacu pada suatu perencanaan pembangunan berkelanjutan wilayah sungai dengan memperhatikan daya dukung fisik ekosistem sungai, serta memperhatikan dampak-dampak yang ditimbulkannya. Proses pembangunan akan berkaitan erat dengan aspek lingkungan, baik lingkungan fisik alam maupun lingkungan sosial budaya yang dinamis.

\section{KESIMPULAN DAN SARAN}

\section{A. Kesimpulan}

Penilaian Potensi dan Daya Tarik Wisata KHDTK Buluh Cina untuk Hamparan sawit memiliki nilai potensi dan daya tarik (3.23) yaitu agak tidak menarik, karena akses masuknya yang sulit, dan status lahannya yang masih belum jelas, serta ada klaim sepihak dari masyarakat yang menyatakan bahwa lahat tersebut milik mereka dan Kawasan Hutan memiliki nilai potensi dan daya tarik (3.39) yaitu agak tidak menarik, karena kawasan hutan yang ada di KHDTK Buluh Cina kurang dari 30\%, selebihnya didominasi dengan sawit. Penilaian Potensi dan Daya Tarik Wisata Pendukung yaitu penilaian Tepian sungai berpasir memiliki nilai potensi dan daya tarik (4.43) yaitu cukup, karena potensi ini baru ditemukan dan belum ada pengelola, fasilitas pendukung. Kawasan ini seperti pantai memiliki pemandangan yang indah dan bisa dijadikan tempat camping. Penilaian Potensi 
Memancing di Sungai memiliki nilai potensi dan daya tarik (4.6) yaitu agak menarik, karena di Sungai Kampar Desa Buluh Cina ini terkenal dengan ikan tapa dan ikan baungnya, bagi yang hobi memancing selalu datang dengan menyewa kapal untuk memacing ikan tersebut.

\section{B. Saran}

Saran dari peneliti adalah status lahan harus diselesaikan terlebih dahulu, agar potensi dan daya tarik wisata dapat dikembangkan. Sebagus apapun potensi yang ada apabila status lahan belum jelas makanya kedepan akan terjadi konflik, serta wisatawan juga akan sulit untuk berkunjung kedalam kawasan tersebut.

\section{DAFTAR PUSTAKA}

Altinay L dan Paraskevas A. 2008. Planning Research in Hospitality and Tourism. Burlington (US): ButterworthHeinemann

Avenzora R. 2008. Ekoturisme-Teori dan Praktek. (ID): BRR NAD-Nias.

Brahmanto, E. 2015. Magnet paket wisata dalam menarik kunjungan wisatawan asing berkunjung ke yogyakarta. Jurnal Media Wisata, Volume 13, Nomor 2, Nov 2015

Damanik J, Weber HF. 2006. Perencanaan Ekowisata dari Teori ke Aplikasi.
Yogyakarta (ID): Penerbit Andi.

Gunn C.A. 1994. Tourism Planning Basics, Concepts, Cases. Third Edition. Tylor \& Francis Ltd. London

Edriana, N. E. (2018). Pemanfaatan Ruang Kawasan Tepi Sungai Untuk Rekreasi Dalam Mendukung Kota Teluk Kuantan Sebagai Waterfront City. 1(2), 97-113.

I Ketut Suwena, I. G. N. W. (2017). Pengetahuan Dasar Ilmu Pariwisata.

Indonesia, P. M. L. H. D. K. R. (2018). Peraturan Menteri Lingkungan Hidup Dan Kehutanan Republik Indonesia Nomor

P.15/Menlhk/Setjen/Kum.1/5/2018

Tentang Kawasan Hutan Dengan Tujuan Khusus. 1-26.

Komarani, U., Satjapradja, O., Salampessy, M. L., Komarani, U., Satjapradja, O., Salampessy, M. L., Study, C., \& Nasional, K. (2015). Identifikasi Dan Penilaian Obyek Daya Tarik Wisata Alam ( Studi Kasus Di Taman Nasional Ujung Kulon ). Jurnal Nusa Sylva, $16(2)$.

Riono Gede Trisoko, R. P. P. (1991). Strategi Pengelolaan Danau Kawah Putih Sebagai Objek Wisata Di Kawasan Ciwidey Oleh Pt . Perhutani ( Persero) Unit Iii Bandung.

Risnayanti, Y. F. (2011). Strategi Promosi Penyelenggaraan Wisata Outbound Dalam Meningkatkan Kunjungan Di Taman Agro Wisata Bukit Naang Kabupaten Kampar.

Sabri, Afisi, L. M. (N.D.). Potensi Prosesi Balimau Kasai Sebagai Atraksi Wisata Budaya Dalam Melestarikan Adat Dan Budaya Di Desa Batu Belah Kecamatan Kampar Kabupaten Kampar. 
Siburian, R. (2006). Pengelolaan Taman Nasional Gunung Leuser Bagian Bukit Lawang Berbasis Ekowisata. 8(1), 6790.

Sri Widowati, N. M. N. (2013). Evaluasi Penerapan Prinsip-Prinsip Dan Kriteria Ekowisata Di Kawasan Taman Wisata Alam Kawah Ijen Banyuwangi. Soshum Jurnal Sosial Dan Humaniora, 3(3), 312-321.

Sugiyono. 2010. Metode Penelitian Bisnis (Pendekatan Kualitatif, Kuantitatif dan $R \& D)$. Bandung (ID) : Alfabeta. 